\title{
Editorial for thematic issues: computational methods in manufacturing
}

\author{
Jean-Philippe Ponthot ${ }^{1} \cdot$ Eric Feulvarch $^{2} \cdot$ Sylvain $_{\text {Drapier }^{3}} \cdot$ Jean-Michel Bergheau $^{2}$
}

Received: 21 January 2016 / Accepted: 22 January 2016/Published online: 3 February 2016

(C) Springer-Verlag France 2016

In a more and more globalized world, the competitiveness requirements of industrial companies force them to develop their products in more and more reduced times and costs. The control of manufacturing processes and of the consequences that they induce on the final products is a critical success factor in this context. Manufacturing processes utilized in industry are numerous and diverse. One can mention:

- direct elaboration processes such as casting, additive manufacturing or liquid composite molding,

- forming processes such as rolling, deep-drawing, blanking, forging, stamping or machining,

Jean-Philippe Ponthot

JP.Ponthot@ulg.ac.be

Eric Feulvarch

eric.feulvarch@enise.fr

Sylvain Drapier

drapier@emse.fr

Jean-Michel Bergheau

jean-michel.bergheau@enise.fr

1 University of Liège, LTAS-Computational Mechanics, 9 Allée de la Découverte, B4000 Liège, Belgium

2 University of Lyon, Ecole Nationale d'Ingénieurs de Saint-Etienne, LTDS, UMR CNRS 5513, 58 rue jean Parot,

42023 Saint-Etienne, Cedex 2, France

3 Ecole des Mines de Saint-Etienne, LGF UMR CNRS 5307, 158 cours Fauriel, CS 62362, 42023 Saint-Etienne, Cedex 2, France
- assembling processes such as welding, riveting, clinching, hemming or bonding,

- heat treatment processes such as quenching, thermochemical surface treatment such as carburinzing or nitriding, thermomechanical surface treatments such as shot peening.

The physical phenomena on which these processes rely pertain to different physics, for example: electromagnetismfluid mechanics-heat transfer-metallurgy-solid mechanics for welding or additive manufacturing processes; heat transferflow in porous media-solid mechanics for composite infusion processes; large strains and strain rates for forming processes, etc. But whatever the considered process, the characterization and the modeling at the adapted scales of the multiphysics couplings involved enabling numerical simulations is of particular interest. Indeed, numerical simulation allows:

- To better understand the role of the process parameters in order to optimize them.

- To determine if a particular process is achievable or not.

- To predict the final state of the component and thus allow more accurate lifetime analyses.

The modeling and the numerical simulation of manufacturing processes thus has fed numerous research axes during recent years and among them:

- The elaboration of complex multiphysics models dedicated to the simulation of particular processes.

- The development of advanced discretization methods, efficient modeling methodologies and robust numerical methods suited to the resolution of very strongly nonlinear problems and to the coupling of several physical phenomena. 
- Establishing efficient and reliable meshing procedures adapted to the representation of the material micro or meso-structure.

- The elaboration of complex constitutive models for materials submitted to extreme thermomechanical loading conditions, under large strains and large strain rates and including microstructure evolution, phase changes or damage.

Numerous international conferences such as ESAFORM, NUMIFORM, NUMISHEET or ICOMP are dedicated to these topics. The technological and scientific importance of "Computational Methods in Manufacturing" justifies that the "International Journal of Material Forming" devotes a thematic issue to this topic. The present issue gathers six peer-reviewed contributions giving an overview of cutting edge works realized in this domain. We hope that this special issue brings to the readers' knowledge new points of view and advances in this very attractive domain where there is still a lot of room for improvements. 